\title{
De rol van de griffier in de verdeling van macht en tegenmacht in het lokaal bestuur*
}

\author{
Petra Paulides-Ruitenberg**
}

\section{Inleiding}

Wie tegenmacht in het openbaar bestuur zegt, komt al snel uit bij Pieter Omzigt en zijn ideeën over een nieuwe bestuurscultuur. In een Nieuwspoort-lezing (2021) stelt hij: 'Macht moet tegenmacht ontmoeten, niet om het gevecht, maar om problemen onder ogen te zien en samen op te lossen. Alleen zo neem je betere besluiten.'

Waar hij zijn pijlen vooral richt op de Haagse machtsbalans, zijn er ook parallellen te trekken met het lokaal bestuur. Want macht en tegenmacht moeten elkaar ook op lokaal niveau ontmoeten om samen betere besluiten te nemen. In het lokaal bestuur is, net als bij de rijksoverheid, de verdeling van de formele macht vastgelegd in wettelijke kaders. Op alle bestuursniveaus zijn het mensen die vanuit hun functie invulling geven aan deze wettelijke kaders. De personen bepalen daarmee de 'couleur locale' van de lokale machtsbalans, ten goede of soms ten kwade.

Dit artikel zal ingaan op het evenwicht van macht en tegenmacht op lokaal niveau. De wettelijke kaders van onder andere de Gemeentewet worden beschreven. Daarnaast wordt ingegaan op de personen die invulling geven aan de lokale machtsbalans. Naast de burgemeester en de secretaris is de griffier een belangrijke actor in het lokaal bestuur. Zij geven samen met de gemeenteraad invulling aan het lokaal bestuur. De griffier ondersteunt de gemeenteraad en zijn leden in zijn taken, maar opereert zelfstandig en onafhankelijk van de lokale politieke partijen. Vanuit mijn eigen ervaring als griffier zal ik vervolgens reflecteren op de vraag wat de griffier kan bijdragen aan de balans tussen macht en tegenmacht in een gemeente. In de laatste paragraaf zal ik ingaan op het vraagstuk hoe de machtsbalans kan worden versterkt door het versterken van de rol van de griffier in het lokaal bestuur.

\section{Het evenwicht van macht en tegenmacht op lokaal niveau}

Sinds de aanpassing van de Gemeentewet in 2002 en de Provinciewet in 2003 werkt het lokaal bestuur via het principe van dualisme. Er is een scheiding aangebracht in de uitvoerende macht van het college en de wetgevende/ controlerende

* $\quad$ Dit artikel is geschreven op persoonlijke titel.

** Drs. ing. Petra Paulides-Ruitenberg is zelfstandig adviseur Lokale Democratie en voormalig griffier. Ze is verbonden aan het programma 'Democratie in Actie', een samenwerkingsprogramma vanuit het ministerie van Binnenlandse Zaken en Koninkrijkrelaties, de Vereniging van Nederlandse Gemeenten en alle beroeps- en belangenverenigingen. 
macht van de gemeenteraad en provinciale staten. Wethouders en gedeputeerden maken sindsdien geen deel meer uit van de volksvertegenwoordiging. Deze wijziging maakte ruimte voor raden en staten om een eigen positie te kiezen ten opzichte van het dagelijks bestuur en om het dagelijks bestuur te controleren. Door deze wetswijziging werd de ambtelijke bijstand voor de gemeenteraad en provinciale staten omgezet in een recht (Vereniging van Griffiers, 2018). De opbouw en intentie van de Gemeentewet en de Provinciewet zijn gelijkwaardig. In dit artikel is gekozen voor een focus op de gemeente en de Gemeentewet om uitleg te geven aan de rol van de griffier.

\section{Tegenmacht in het lokaal bestuur}

De kern van het dualisme in het lokaal bestuur is een duidelijke afbakening van de rollen van de bestuursorganen, met daaraan gekoppeld ook het juiste instrumentarium om invulling te geven aan de rollen. Door deze stelselwijziging is tegenover macht van het college op de uitvoering, ook de kaderstellende en de controlerende rol vanuit de volksvertegenwoordigende rol van de gemeenteraad gezet. Vooral de ruimte voor controle op uitvoering bepaalt de ruimte voor tegenmacht, stelt Van Ostaaijen $(2018,109)$. Over tegenmacht schrijft hij: 'Het inrichten van het stelsel van macht en tegenmacht voorkomt dat één bestuurslaag, organisatie of actor zijn wil te dominant kan doordrukken. Het organiseren van tegenmacht is net zo wezenlijk voor de kwaliteit van de lokale democratie als het organiseren van een goede verbinding tussen lokale samenleving en lokaal bestuur.' Er kan onderscheid gemaakt worden tussen tegenmacht binnen de politieke democratie, waarbij het gaat om institutionele vormen van tegenmacht zoals interne controle van de ambtelijke organisatie, controle van de gemeenteraad en de vorming van (nieuwe) politieke partijen, en vormen gerelateerd aan of los van de politieke democratie, zoals bezwaar- en beroepsprocedures, de rekenkamer, de ombudsman, de media en de lokale samenleving (Van Ostaaijen, 2018, 114). Deze indeling in verschillende vormen van tegenmacht helpt bij het kijken naar de machtsbalans in het lokaal bestuur.

De wijze waarop invulling wordt gegeven aan de verschillende vormen van institutionele tegenmacht is een signaal voor hoeveel ruimte er is voor tegenmacht in een gemeente. Een positieve houding van ambtenaren en politici ten opzichte van tegenmacht blijkt uit de steun aan meer institutionele vormen van tegenmacht (Van Ostaaijen, 2018). Tegenmacht moet immers ook deels binnen de politieke democratie worden georganiseerd. De functie van de griffier behoort tot het instrumentarium van de gemeenteraad en zijn leden. Hij of zij is de facilitator van de rollen van de raad in het bestuurlijk samenspel. De griffier geeft daarmee mede vorm en inhoud aan het stelsel van macht en tegenmacht in de politieke democratie. Daarnaast kan een griffie ook vormen gerelateerd aan of los van de politieke democratie ondersteunen, zoals de rekenkamer. De organisatie van een vorm van rekenkamer valt standaard ook binnen het takenpakket van de griffie. Dit geldt ook voor contacten met of het beschikbaar stellen van informatie aan de media of lokale samenleving namens de gemeenteraad. 


\section{Ruimte voor de gemeenteraad}

In 2016 deed de Raad voor het Openbaar Bestuur onderzoek naar de tijdsbesteding van raadsleden. Hij concludeert dat raadsleden steeds meer tijd kwijt zijn aan hun werk als raadslid, gemiddeld 15,9 uur per week. Ze hebben moeite om een betekenisvolle rol te kunnen spelen in de gemeentelijke besluitvormingsprocessen door de complexiteit van dossiers en besluitvormingsprocessen (Raad voor het Openbaar Bestuur, 2016). Er is dus hulp nodig om invulling te geven aan hun taken. Schram, Van Twist en Van der Steen (2017) onderzochten de beschikbare hulpbronnen voor de gemeenteraad en het gebruik van die bronnen. Ze beschrijven vier soorten ondersteuning: gericht op extra capaciteit, aanvullende deskundigheid, frisse inspiratie en belevingsinformatie. De aanwezigheid van hulpbronnen en de mogelijkheid om ze in te zetten voor ondersteuning is voor raadsleden belangrijk. Gebrek aan tijd en kennis blijkt de belangrijkste reden te zijn om hulptroepen in te zetten. Raadsleden geven aan dat vooral de griffier hen wijst op de procesmatige mogelijkheden voor ondersteuning. Ze houden zichzelf verantwoordelijk voor het zoeken naar inhoudelijke ondersteuning. Zij stellen dat het toevoegen van hulpbronnen kan helpen in het creëren van evenwichtigere machtsbalans (Schram e.a., 2017).

\section{Ondersteuning van de controlerende rol}

De controlerende rol van de gemeenteraad is een essentiële taak om de machtsbalans in het lokaal bestuur op orde te houden. Schram e.a. (2017) stellen dat de controlerende rol van de gemeenteraad onder druk staat. Raadsleden moeten sinds de decentralisaties meer en moeilijker werk verrichten met gelijke tijd en beschikbare capaciteiten. Daarnaast spreekt het controlerende werk raadsleden minder aan. Zij geven de voorkeur aan het investeren van hun tijd in kaderstellende en volksvertegenwoordigende taken (Schram e.a., 2017).

Invulling geven aan de controlerende rol is ook geen makkelijke taak. Het is vaak tijdsintensief, vraagt om enige kennis of begrip van de wettelijke en financiële kaders, en vraagt daarnaast ook doorzettingsvermogen van raadsleden. Ooit vroeg een raadslid in mijn gemeente om inzage in de uitgifte van een groot project. Het gevolg was dat hij bedolven werd onder de documenten. Hij heeft veel tijd nodig gehad om de gewenste informatie daaruit te halen en door te vragen op wat hij vond. Pas na weken onderzoek was hij zover om het college ter verantwoording te roepen. Dit deed mij inzien dat we veel van onze volksvertegenwoordigers verwachten in hun controlerende rol. Een vraag die bij mij bleef hangen was: kunnen raadsleden deze taak vormgeven zonder de juiste ondersteuning? Het raadslidmaatschap is tenslotte een 'lekenbaan' (Loots e.a., 2010). Raadsleden zijn gekozen inwoners die naast hun dagelijkse werkzaamheden in hun vrije tijd ruimte maken voor het raadswerk. Voldoende ondersteuning en de beschikbaarheid van instrumentarium zijn daarom ook belangrijke randvoorwaarden om invulling te kunnen geven aan deze taak (Schram e.a., 2017). 


\section{De functie van de griffier in het lokaal bestuur}

De functie van de griffier is in 2002 opgenomen in de Gemeentewet (Gemw). ${ }^{1}$ Artikel 107 lid 1 Gemw schrijft voor dat de raad de griffier aanwijst. In samenspraak met de gemeenteraad wordt invulling geven aan de gewenste ondersteuning door de griffie(r). De invulling van de taak als griffier is door de wetgever voor een groot deel open gelaten. De Gemeentewet bepaalt alleen dat de griffier de raad en de door de raad ingestelde commissies bij de uitoefening van hun taak terzijde staat, ${ }^{2}$ en dat de griffier in de vergaderingen van de raad aanwezig is. ${ }^{3}$ Aanvullend stelt de raad via een instructie nadere regels op over de taken en de bevoegdheden van de griffier en de organisatie van de griffie. ${ }^{4}$

De Gemeentewet biedt hiermee de benodigde ruimte voor een lokale invulling van de rol van de griffier. Uit onderzoek van Schaap e.a. (2018) blijkt dat griffiers met name actief zijn in vier taakvelden: secretariële taken, faciliteren, vertegenwoordigen van de raad, en adviseren van raadsleden. $\mathrm{Zij}$ onderscheiden daarmee verschillende griffiersprofielen, afhankelijk van het soort ondersteuning dat wordt geboden. Belangrijk is dat het profiel van de griffier past bij de ambities van de raad en zijn leden. Om dit samenspel tussen raad en griffier vorm te geven is regelmatig contact nodig. Naast formele momenten is met name ook het informele overleg tussen leden en griffie van belang (Paulides-Ruitenberg, 2020). Door goed voeling te houden met wat er in de raad speelt kan de griffier invulling geven aan het adviseurschap en de gewenste ondersteuning van de rollen van de gemeenteraad.

\section{Griffiersprofiel}

Naast de ondersteuning van de rollen van de gemeenteraad heeft een griffier een rol in de interne bestuurlijk en ambtelijke verhoudingen, draagt de griffier zorg voor de profilering van de raad en geeft hij of zij leiding aan de griffie (Vereniging van Griffiers, 2016). Belangrijk in deze spilfunctie is dat de griffier en de griffie onafhankelijk en neutraal kunnen opereren en adviseren. Griffiers worden door gemeenteraden zorgvuldig uitgezocht en in de selectieprocedure bevraagd op deze kwaliteiten. Wanneer je zoekt naar mensen die passen op dit profiel, is het goed te verklaren dat uit onderzoek (Schaap e.a., 2018) blijkt dat veel griffiers neigen naar een meer beleidsinhoudelijke en strategische invulling van hun taak. Dit is ook de gewenste ontwikkelrichting die vanuit de Vereniging van Griffiers samen met de Nederlandse Vereniging voor Raadsleden is ingezet voor de functie van griffier (Vereniging van Nederlandse Gemeenten, 2021). Toen op 16 september 2021 door het bestuur van de Vereniging van Nederlandse Gemeenten werd ingestemd met één strategisch profiel voor de griffier, sprak de Vereniging van Griffiers van 'een mooie mijlpaal' (Vereniging van Griffiers, 2021).

\section{Ondersteuning van de gemeenteraad}

Om invulling te geven aan de wens van een goede en strategische ondersteuning voor de gemeenteraad is voldoende menskracht en budget nodig. Juist op dit punt blijken raden niet goed voor zichzelf te willen of te kunnen zorgen, zo concludeert de Raad voor het Openbaar Bestuur (2020, 35). 
'Waarom zorgen decentrale volksvertegenwoordigingen niet voor goede ondersteuning? De raad ziet als belangrijkste reden een grote handelingsverlegenheid bij gemeenteraden en provinciale staten om in zichzelf te investeren. Bij de afweging waaraan schaarse publieke middelen moeten worden besteed (jeugdzorg of toch het zwembad?) is het, al dan niet aangewakkerd door of uit angst voor de publieke opinie of sociale media, een veelvoorkomende reflex om het goede voorbeeld te willen geven en te "snijden in eigen vlees": het bezuinigen op de griffie, het korten op het budget van de rekenkamer, het schrappen van de fractieondersteuning, een stop op cursussen en opleiding.'

De gemiddelde bemensing van een griffie in een gemeente bedraagt momenteel $2,85 \mathrm{fte}$, inclusief de griffier zelf. Op de vraag of de griffie van voldoende omvang is om aan de vraag van de gemeenteraad te voldoen, geeft 41 procent van de respondenten van het onderzoek naar de Staat van het Bestuur in 2018 aan dat dit niet het geval is (Ministerie van Binnenlandse Zaken en Koninkrijksrelaties, 2019). Met minder dan drie mensen is een inhoudelijke ondersteuning op de vele beleidsterreinen waar een gemeenteraad mee van doen heeft, te veel gevraagd, stelt Hessels (2020). Ook de griffiers voelen dat. Er is een motie op het congres van de Vereniging van Griffiers (Duursema e.a., 2019) uitgesproken om steun te verwerven voor een minimale omvang voor de griffies bij het ministerie van Binnenlandse Zaken en Koninkrijkrelaties, de Vereniging van Nederlandse Gemeenten, de andere beroeps- en belangenverengingen en de werkgeverscommissies. Met name in kleine gemeenten werd het aantal fte als onvoldoende gezien om ook de raad in zijn rollen en taken te ondersteunen. Dit heb ik ook zelf ervaren. Met 1,2 fte waren we op onze griffie blij dat we de dagelijkse taken op orde hadden. Er was amper ruimte voor aanvullende vragen of verzoeken vanuit de raad. Daarmee komt de raad in een reactieve positie ten opzichte van het college. Dit komt de machtsbalans in een gemeente vaak niet ten goede.

\section{Hoe zou macht en tegenmacht lokaal (en de functie van de griffie) versterkt kunnen worden?}

De institutionele vormen van tegenmacht op het lokaal bestuur zouden zowel binnen de politieke democratie als daarbuiten voldoende ruimte moeten krijgen. Zoals eerder benoemd kan de griffier met name een toegevoegde waarde leveren binnen de politieke democratie ter ondersteuning van de gemeenteraad en het controle-instrumentarium van de gemeenteraad. Wanneer de griffier en de griffie hiervoor ruimte beschikbaar hebben, kunnen drempels zoals het gebrek aan tijd en deskundigheid voor de gemeenteraad worden verlaagd. Dit zou de keuze voor controle en de kwaliteit van de controle ten goede moeten komen. De Raad voor het Openbaar Bestuur roept op om normen te formuleren voor deze ondersteuning. 'Bepaal wat het mag kosten en leg de normen vast. Zorg dat middelen herkenbaar beschikbaar zijn en stimuleer naleefgedrag' (Raad voor het Openbaar Bestuur, 2020). Deze oproep is opvallend, want waarom zijn normen nodig? Zien raadsleden de meerwaarde niet van hun ondersteuning, is het een budgetkwestie of is het een combinatie van beide punten die raadsleden handelingsverlegen maakt? Deze 
vraagstelling lijkt nog onvoldoende onderzocht. De Raad voor het Openbaar Bestuur (2020) maakt in zijn rapport hierover een belangrijk statement: 'Mensen, dus ook raadsleden, kunnen alleen worden geholpen als ze geholpen willen worden.' Hiermee leggen ze de verantwoordelijkheid voor het vormgeven van de ondersteuning ook terug waar het hoort, namelijk bij de volksvertegenwoordigers. Het is wenselijk dat raadsleden daarom zichzelf en elkaar regelmatig de vraag stellen: Neem ik mijn rol en de institutionele tegenmacht in mijn gemeente serieus? Wat zou ik of zouden we kunnen doen om meer ruimte te kunnen geven aan de tegenmacht in mijn gemeente?

\section{Vergroten van de ruimte voor tegenmacht}

Het onderkennen van de noodzaak van ruimte voor tegenmacht is een eerste stap. Het gesprek over wat tegenmacht op lokaal niveau inhoudt, kan door alle betrokken actoren worden opgestart. Een burgemeester, een secretaris of de griffier kan het agenderen in een ambtelijk overleg. Raadsleden kunnen het thema van tegenmacht agenderen in politieke overleggen. Het is waardevol en nodig om met elkaar te reflecteren op de lokale machtsbalans. Het kan het startpunt zijn om gezamenlijk te kijken naar de ruimte die beschikbaar is in kennis, tijd en budget voor de verschillende tegenmachten.

De griffier zelf is onderdeel van de politieke institutionele tegenmacht, maar hij of zij kan ook bijdrage aan het vormgeven en faciliteren van tegenmacht in het lokaal bestuur. De machtsbalans in het lokaal bestuur zou gebaat zijn bij een griffier die een actieve rol pakt in het gesprek over en het faciliteren van de verschillende typen tegenmachten. 'Niet om het gevecht, maar om problemen onder ogen te zien en samen op te lossen', aldus Pieter Omzigt. Een griffier kan onafhankelijk adviseren hoe de taken op te pakken, maar ook kennis en inzet leveren voor de uitvoering deze taken. Daarnaast kan hij of zij een belangrijke rol vervullen in het zorgen voor neutrale, complete en begrijpelijke informatiestromen naar de verschillende tegenmachten, zoals naar de gemeenteraad in zijn controlerende rol of naar de rekenkamer.

Door inzet van de griffier en de griffie op hun taken staat de gemeenteraad sterker in zijn rol. Raadsleden die de meerwaarde van de griffie(r) zien en ervaren, zetten deze ook in. Een onafhankelijke griffier ontzorgt en voegt kwaliteit toe in de uitvoering van de controlerende taak van de gemeenteraad. De griffier verschuift door dit type ondersteuning van procesondersteuner naar een meer tactische en strategische invulling van zijn of haar rol. De griffiers zijn klaar voor deze stap. Er ligt inmiddels één strategisch profiel voor de griffier klaar (Vereniging van Griffiers, 2021). De griffie van morgen kan daarmee ondersteuning bieden aan meerdere primaire processen en rollen van de gemeenteraad. Ze staat de raad en de leden bij waar zij het nodig hebben (Pruim, Broer \& Loots, 2020). Er is echter een belangrijke mits: dit kan alleen wanneer gemeenteraden de griffier voorzien van voldoende ruimte in budget en handelingsperspectief. Alleen dan kunnen de griffier en de griffie ook helpen met de verdere ontwikkeling van macht en tegenmacht in het lokaal bestuur. 


\section{Noten}

1 Artikel 100 lid 1 Gemw.

2 Artikel 107a lid 1 Gemw.

3 Artikel 107b Gemw.

4 Artikel 107e lid 1 en 2 Gemw.

\section{Literatuur}

Duursema, B., Randsdorp, L., Adriaanse, K., Nubé, H., ... Heide, F. van der (2019). Een sterke raad verdient een stevige griffie( $r$ ). Motie: congres Vereniging van Griffiers.

Hessels, J. (2020). Advies ondersteuning gemeenteraad, t.b.v. de Raad voor het openbaar bestuur. www.raadopenbaarbestuur.nl/documenten/publicaties/2020/11/05/goedeondersteuning-sterke-democratie, geraadpleegd op 24 september 2021.

Loots, J., Wildeman, G.T., Smolders, T.A.J.M., \& Freeke, R.M. (2010). Ik raadslid. Maarsbergen: Necker van Naem B.V.

Ministerie van Binnenlandse Zaken en Koninkrijksrelaties (2019). Staat van het Bestuur 2018. Den Haag: Kennisbank Openbaar Bestuur.

Omzigt, P. (2021). Lezing Nieuwpoort: Over macht en tegenmacht. Den Haag: CDA.

Ostaaijen, J. van (2018). Tussen eerste overheid en tweederangsdemocratie, het functioneren van de lokale democratie in Nederland. Den Haag: Boom bestuurskunde.

Paulides-Ruitenberg, P. (2020). De griffier \& de werkgeverscommissie, gesprekspunten voor een goed samenspel. Den Haag: Vereniging van Griffiers.

Pruijm, J.D., Broer, G.J., \& Loots, J. (2020). De griffie van morgen: ruimtemakers gezocht. Almere: Raad van Almere.

Raad voor het Openbaar Bestuur (2016). 15,9 uur: De verbindende rol van het raadslid in een vitale democratie. Den Haag: Zijlstra Drukwerk.

Raad voor het Openbaar Bestuur (2020). Goede ondersteuning, sterke democratie: Over de ondersteuning van decentrale volksvertegenwoordigingen. Den Haag: Studio Tint.

Schaap, L., Kruyen, P., Hulst, M. van, \& Ostaaijen, J. van (2018). De griffier in gemeenteland. Bestuurswetenschappen, 72 (1): 5-25.

Schram, J., Twist, M. van, \& Steen, M. van der, (2017). Raad en hulptroepen, hefbomen ter versterking van de controlerende rol van de gemeenteraad. Den Haag: Vereniging voor Raadsleden/Nederlandse School voor Openbaar Bestuur.

Vereniging van Griffiers (2016). Functiebeschrijving griffier. Den Haag: Vereniging van griffiers.

Vereniging van Griffiers (2018). De (rechts)positie van de griffier anno 2018. Utrecht: Eburon.

Vereniging van Griffiers (2021). Eén griffiersprofiel in HR21. Bericht uit Headlines 16 september 2021. Den Haag: Vereniging van griffiers.

Vereniging van Nederlands Gemeenten (2021). Normfunctie raadsgriffier uit HR21. https:// vng.nl/nieuws/normfunctie-raadsgriffier-uit-hr21, geraadpleegd op 23 september 2021. 